\title{
Trajetórias diaspóricas indígenas no tempo presente: terras e territórios Atikum, Kamba e Kinikinau em Mato Grosso (do Sul)
}

\begin{abstract}
Resumo
Ao refletir sobre terras e territórios no Brasil e na América Latina, a partir dos sujeitos sociais, da memória histórica e das políticas públicas no tempo presente, entra em cena a questão das terras indígenas. Mato Grosso do Sul, estado brasileiro localizado na região Centro-Sul, tem atualmente uma das maiores populações indígenas do país, de acordo com o último recenseamento, realizado pelo Instituto Brasileiro de Geografia e Estatística (IBGE) em 2010. É, também, um dos estados em que há intensos e contínuos conflitos entre fazendeiros e indígenas, situação que se arrasta, pelo menos, desde o século XIX, especialmente após o final do conflito conhecido como Guerra do Paraguai (1864-70). Compreender as trajetórias das diversas sociedades indígenas presentes no antigo "sul do Mato Grosso" não é tarefa das mais simples, haja vista que, historicamente, essas populações estiveram submetidas a um gradativo e violento processo de concentração em pequenas porções de terras. Este artigo apresenta trajetórias diaspóricas e processos de territorialização/desterritorialização/reterritorialização ocorridos na história dos Atikum, Kamba e Kinikinau, que, em pleno século $\mathrm{XXI}$, ainda lutam por uma visibilidade que lhes garanta respeito a direitos que têm sido negados sistematicamente. Para a compreensão dessas presenças indígenas em Mato Grosso do Sul no tempo presente foram utilizados dados obtidos em trabalhos de campo, realizados pelo autor nos últimos 20 anos, além de acurada revisão de literatura, o que revela percalços - bem como estratégias/táticas de sobrevivências física e cultural - das trajetórias vividas pelos grupos ao longo do século XX e no início do século XXI.
\end{abstract}

Palavras-chave: Emigração e Imigração - Aspectos Sociais. Índios da América do Sul - Posse da Terra. Mato Grosso do Sul.

\section{Para citar este artigo:}

SILVA, Giovani José da. Trajetórias diaspóricas indígenas no tempo presente: terras e territórios Atikum, Kamba e Kinikinau em Mato Grosso (do Sul). Tempo e Argumento, Florianópolis, v. 11, n. 28, p. 98 -126, set./dez. 2019. 


\title{
Indian diasporic paths in the present time: Atikum, Kamba, and Kinikinau territories in Mato Grosso (do Sul), Brazil
}

\begin{abstract}
When thinking of lands and territories in Brazil and Latin America, starting from the social subjects, historical memory, and public policy in the present time, the issue of Indian lands comes into play. Mato Grosso do Sul, a Brazilian state located in the Central-South region, currently has one of the largest Indian populations in the country, according to the latest census, conducted by the Brazilian Institute of Geography and Statistics (Instituto Brasileiro de Geografia e Estatística [IBGE]) in 2010. It is also one of the states where intense and ongoing conflicts between farmers and Indians take place, a situation that persists, at least, since the 19th century, especially after the end of the conflict known as the Paraguayan War (1864-70). Grasping the paths of the various Indian societies that occupy the former 'southern Mato Grosso' is not an easy task, given that, historically, these populations have been subject to a gradual and violent process of concentration in small portions of land. This article introduces diasporic paths and territorialization/deterritorialization/reterritorialization processes occurring in the history of the Atikum, Kamba, and Kinikinau peoples, which, even in the 21st century, still struggle for a visibility that guarantees them respect for rights that have been systematically denied. To see this Indian presence in Mato Grosso do Sul in the present time, data obtained through fieldwork, carried out by the author over the last 20 years, were used, as well as an accurate literature review, something which reveals obstacles - as well as physical and cultural survival strategies/tactics - to the paths followed by the groups throughout the 2oth century and in the early 21st century.
\end{abstract}

Keywords: Emigration and Immigration - Social Aspects. South American Indians - Land Possession. Mato Grosso do Sul. 


\section{Introdução}

Após o final da Guerra do Paraguai, ou Guerra da Tríplice Aliança (1864-70), o Mato Grosso do Sul, antigo "sul do Mato Grosso", tornou-se palco de intensos e contínuos conflitos entre fazendeiros e indígenas ${ }^{1}$. Localizado na região Centro-Sul, é um dos estados da Federação brasileira que tem, atualmente, uma das maiores populações indígenas do país (BRASIL, 2010). Compreender a trajetória espaço-temporal das diversas sociedades indígenas no espaço físico compreendido pelo "sul do Mato Grosso" é uma tarefa complexa, haja vista que, historicamente, essas populações estiveram submetidas a um gradativo e violento processo de concentração em pequenas porções de terras. À exceção dos Kadiwéu, que detêm o usufruto de mais de meio milhão de hectares em Porto Murtinho-MS (JOSÉ DA SILVA, 2014), fronteira do Brasil com o Paraguai, os demais grupos lutam para reaver territórios tradicionais usurpados há tempos. Existem, ainda, aqueles que sequer ocupam territórios próprios, como é o caso dos Kinikinau, Kamba e Atikum² - abordados neste artigo.

Até o início do século XXI, quando se enunciavam as populações indígenas em terras sul-mato-grossenses, imediatamente surgiam referências a apenas 5 etnias: a) Guarani (grupos Kayowá e Ñandeva); b) Guató; c) Kadiwéu; d) Ofayé; e e) Terena. Um perturbador silêncio se verificava em relação a outros 3 grupos: a) Atikum (oriundo de Pernambuco); b) Kamba (migrante da Bolívia); e c) Kinikinau (confundido com Terena durante a maior parte do século XX) - como se, de fato, não existissem ${ }^{3}$. O texto do sociólogo Paulo Eduardo Cabral (2002, p. 33), de ampla circulação em escolas públicas de Mato Grosso do Sul no início do século XXI, por exemplo, indicava esse não reconhecimento:

São cinco os povos oficialmente reconhecidos [em Mato Grosso do Sul]: Guató, Kadwéu [Kadiwéu], Terena, Guarani/Kaiowá [Guarani-Kayowá e Guarani-Ñandeva] e Ofaié [Ofayé] [...] os que ainda não obtiveram reconhecimento oficial são os Kamba, Kinikinau e Atikum.

\footnotetext{
${ }^{1} \mathrm{O}$ estado de Mato Grosso do Sul foi desmembrado do antigo estado de Mato Grosso em 11 de outubro de 1977 e teve seu primeiro governo instalado em $1^{\circ}$ de janeiro de 1979 (BITTAR, 1999).

${ }^{2}$ Alerta-se que, exceto nas citações, em todas as nomenclaturas referentes às sociedades indígenas foram seguidas as normas da Associação Brasileira de Antropologia (ABA) (cf. SCHADEN, 1976, p. XI-XII).

3 Uma recente publicação científica informa que são 11 as etnias indígenas em Mato Grosso do Sul no tempo presente: a) Atikum; b) Ayoreo; c) Chamacoco (Ishir); d) Guarani (Kayowá); e) Guarani (Ñandeva); f) Guató; g) Kadiwéu; h) Kamba; i) Kinikinau; j) Ofayé; e k) Terena (CHAMORRO; COMBÈs, 2015).
} 
Crê-se que tal silêncio se deva, sobretudo, ao fato dessas populações indígenas ainda não ocuparem terras identificadas, delimitadas, demarcadas e/ou homologadas no estado.

À omissão do órgão indigenista oficial, a Fundação Nacional do Índio (Funai), soma-se a indiferença acadêmica, por parte de pesquisadores, sobretudo da História Indígena e da Antropologia. Assim, este artigo apresenta trajetórias diaspóricas e processos de territorialização/desterritorialização/reterritorialização ocorridos na história dos Atikum, dos Kamba e dos Kinikinau, que, em pleno século XXI, ainda lutam por uma visibilidade que lhes garanta o respeito a direitos que têm sido negados sistematicamente ao longo do tempo. Para tanto, utilizam-se dados obtidos em trabalhos de campo realizados pelo autor nos últimos 20 anos, além de acurada revisão de literatura e pesquisa documental, que revelam percalços, percepções e perspectivas dos grupos indígenas em relação ao passado, ao presente e (quiçá) ao futuro em Mato Grosso do Sul, um estado reconhecidamente omisso em relação à questão de terras e territórios indígenas.

Os Atikum vivem em um território tradicional, a Serra do Umã, localizado em Pernambuco, de onde parte do grupo saiu entre as décadas de 1970 e 80, fugindo da seca e da extrema violência na região, encravada no chamado "Polígono da Maconha" (JOSÉ DA SILVA, 2000, 2005, 2019). Os Kinikinau viviam em terras da Reserva Indígena Kadiwéu, na Aldeia São João, desde o início dos anos 1940, tendo-se distribuído por aldeias Terena nas últimas décadas. Dados como “extintos” por antropólogos e indigenistas ao longo do século XX, hoje buscam retomar parte de seu vasto território tradicional, localizado entre os municípios sul-mato-grossenses de Miranda e de Corumbá (JOSÉ DA SILVA; BOLZAN; SOUZA, 2017). Já os Kamba chegaram a Corumbá a partir da década de 1950 e estabeleceram-se, desde então, na periferia daquela cidade, no "Reduto São Francisco", considerado pelos regionais uma "favela" e representado/territorializado pelos próprios indígenas como uma aldeia, seu pueblito (PENTEADO, 1980; R. H. SILVA, 2009; JOSÉ DA SILVA, 2012).

Nos últimos anos, um considerável número de trabalhos acadêmicos a respeito de populações indígenas que habitam o atual Mato Grosso do Sul foi produzido sob a forma 
de monografias, dissertações e teses. Esse fato se deveu, sobretudo, à expansão e à implantação de programas de pós-graduação nas universidades da região Centro-Oeste, a partir do final dos anos 1990. Dessa forma, estudos a respeito dos Guarani (Kayowá e Ñandeva), Guató, Kadiwéu, Ofayé e Terena, além de outros grupos, ganharam espaço acadêmico graças à dinamização da área de pesquisa em História Indígena, pois, como afirma J. E. Oliveira (2001, p. 124), “em Mato Grosso do Sul, assim como em outros estados brasileiros, nunca os povos indígenas estiveram tão presentes no campo dos historiadores". Apesar disso, ainda são poucos os trabalhos que versam sobre os Atikum, os Kinikinau e os Kamba ou mesmo que façam referência a essas etnias, invisibilizadas no campo das políticas públicas e, inclusive, academicamente.

Como também pontua J. E. Oliveira (2018, p. 29):

Pode-se afirmar com segurança que é marcante a presença indígena na história, na cultura e no cotidiano da vida de grande parte da população do estado [de Mato Grosso do Sul]. Esta presença está explícita nos modos de ser e nas próprias identidades da população sul-matogrossense. Mas ela também se faz presente nos problemas políticos, econômicos e socioculturais que constituem um desafio a ser enfrentado na busca de soluções pela sociedade organizada e pelos governos.

É neste contexto que especialistas de diversas áreas do conhecimento, como antropólogos, arqueólogos, historiadores e outros cientistas sociais, dedicam-se cada vez mais ao estudo de temáticas relacionadas aos povos indígenas.

Para melhor compreensão dessas presenças indígenas em Mato Grosso do Sul, mostra-se necessária a discussão sobre alguns conceitos que podem ser aplicados às trajetórias espaço-temporais vividas pelos grupos ao longo do século XX e que resultaram em suas presenças no atual cenário étnico sul-mato-grossense. Dentre os conceitos, pode-se mencionar o de diáspora, pensado e formulado pelo sociólogo e teórico cultural Stuart Hall. A diáspora - cujo conceito fechado, segundo Hall (2008, p. 32-33, grifo do autor), "se apoia sobre uma concepção binária de diferença. [...] Porém, [...] a diferença [...] não funciona através de binarismos, fronteiras veladas que não separam finalmente, mas são também places de passage, e significados que são posicionais e relacionais, 
sempre em deslize ao longo de um espectro sem começo nem fim"4 - e os conceitos de terras e de territórios indígenas precisam ser (re)pensados à luz das contribuições da Antropologia, do Direito e da Geografia, dentre outras áreas do conhecimento. Sinalizase, assim, a busca por novas representações sociais e os rearranjos e conflitos em torno delas.

Em se tratando de populações indígenas, nos últimos anos, a Antropologia tem trabalhado com os conceitos de "territorialização" e de "territorialidade" para a compreensão das trajetórias históricas e diaspóricas ameríndias (LITTLE, 2002). A Geografia, por sua vez, com os trabalhos de Rogério Haesbaert (2004, 2014), além de outros, afirma que, a partir de determinada concepção de território, propõe-se a definição de desterritorialização a ser discutida:

[...] Para uns, por exemplo, desterritorialização está ligada à fragilidade crescente das fronteiras, especialmente das fronteiras estatais - o território, aí, é sobretudo um território político. Para outros, desterritorialização está ligada à hibridização cultural que impede o reconhecimento de identidades claramente definidas - o território aqui é, antes de tudo, um território simbólico, ou um espaço de referência para a construção de identidades (HAESBAERT, 2004, p. 35).

Em termos do Direito, é importante ressaltar que todas as terras indígenas homologadas no Brasil pertencem à União. De acordo com a Constituição Federal (BRASIL, 1988, artigos 231, 232 e outros), aos indígenas é garantido o usufruto exclusivo das riquezas do solo, dos rios e dos lagos existentes nelas, sendo inalienáveis e indisponíveis e os direitos sobre elas imprescritíveis. As garantias legais conquistadas em 1988 - sob forte ameaça no tempo presente - já vinham sendo, de alguma forma, asseguradas pelas constituições republicanas ou por emendas constitucionais de 1934, 1937, 1946, 1967 e 1969. A partir dessas garantias - da conquista do direito à terra e da configuração social e simbólica de um território próprio -, as identidades étnicas se afirmam e são (re)elaboradas, ressignificadas pelas diferentes sociedades indígenas, por meio da memória social, intrinsecamente relacionada à construção das identidades.

\footnotetext{
4 J. P. de Oliveira (2004, p. 31-32; grifo do autor), por sua vez, aponta que "a diáspora remete àquelas situações em que o indivíduo elabora sua identidade pessoal com base no sentimento de estar dividido entre duas lealdades contraditórias, a de sua terra de origem (home) e do lugar onde está atualmente, onde vive e constrói sua inserção social".
} 
Assim, o direito às memórias dos diferentes grupos indígenas é colocado na perspectiva da memória social (FENTRESS; WICKHAM, 1992), privilegiando-se, dentre outras fontes, as narrativas dos próprios sujeitos sociais, durante muito tempo esquecidos/obliterados/silenciados/excluídos.

\section{"Excluídos" da História Indígena em Mato Grosso (do Sul): Atikum, Kamba e Kinikinau}

Segundo o antropólogo Rodrigo de A. Grünewald (1993), os Atikum fazem parte de um conjunto de grupos indígenas nordestinos que, menosprezados pela etnologia clássica por serem considerados "menos importantes" ou "aculturados", só começaram a ter visibilidade a partir da segunda metade dos anos 1980. Esses grupos eram vistos, ainda, como "restos" ou "resíduos" de uma etnia ancestral, recebendo, por isso, o rótulo de "remanescentes indígenas". Foi somente a partir do início da década de 1990 que os antropólogos críticos do paradigma da aculturação passaram a realizar pesquisas e estudos sobre populações indígenas no Nordeste do Brasil, tornando-os mais conhecidos e foco de diversos debates acadêmicos (BARRETTO FILHO, 1994). Os Atikum da Serra do Umã em Pernambuco - e uma parte do grupo que hoje vive em Mato Grosso do Sul encontram-se entre tais populações.

A terra indígena Atikum se localiza no sertão pernambucano, atual município de Carnaubeira da Penha. Os membros da "Comunidade Indígena de Atikum-Umã" se autodenominam caboclos da Serra do Umã, em referência a uma ancestralidade comum. Os Atikum são falantes apenas da língua portuguesa e dados coletados por Grünewald (1993) apontam a imprecisão de situar o antigo idioma dos Umã em uma classificação linguística correta. Quanto à história do grupo, pode-se afirmar que, a partir da passagem do século XVII para o XVIII, a região geográfica ocupada atualmente pelos Atikum em Pernambuco se tornou palco de inúmeros conflitos, entre indígenas e não indígenas, provocados sobretudo pela frente de expansão pastoril.

Em Mato Grosso do Sul, os Atikum se concentram no município de Nioaque, em terras da Reserva Indígena Terena (aldeias Água Branca, Brejão, Cabeceira e Taboquinha). 
Ali vivem pouco mais de 100 indivíduos Atikum, liderados até recentemente por Aliano José Vicente (falecido em 2018), um dos primeiros indígenas dessa etnia a chegar ao estado, em meados dos anos 1980. Antes, porém, de estabelecer-se entre os Terena, os Atikum passaram por fazendas nos estados de Minas Gerais, São Paulo e Paraná, onde alguns teriam sido submetidos a trabalho análogo à escravidão. Vivem, sobretudo, da agricultura e do trabalho em fazendas e são chamados pejorativamente, por indígenas Terena e não indígenas, de "terra seca". Muitos desconfiam, inclusive, que, por causa da aparência física, os Atikum não sejam sequer indígenas. A fala de Aliano Vicente, contudo, revela a clareza que os Atikum têm sobre quem são: "o mais importante é eu saber quem eu sou. Não importa que me chamem de 'baiano' ou 'terra seca'. Eu sei da verdade, eu sei quem eu sou: eu sou caboclo da Serra do Umã" (JOSÉ DA SILVA, 2019, p. 57).

O fato de serem chamados de "terra seca" ainda hoje revela que, de alguma forma, são diferenciados de outros grupos, especialmente dos Terena, com quem convivem há tempos em uma relação intersocietária nem sempre pacífica. Utilizam como elemento de adscrição, por excelência, o ritual do Toré, uma tradição que no passado tomaram de empréstimo dos Tuxá, da Bahia. Trata-se, portanto, de um grupo étnico que elegeu categorias de pertencimento e exclusão de seus membros, com base em relações específicas. Os Atikum, ou caboclos da Serra do Umã, veem-se como indígenas e fazem-se vistos pelos outros assim, em uma verdadeira "luta" pelo reconhecimento de uma identidade étnica e cultural que tem tudo pela aparência física para ser negada como legitimamente indígena (pele escura, cabelos encaracolados etc.).

Há, até o momento, poucos trabalhos acadêmicos sobre os Atikum em Mato Grosso do Sul, destacando-se os elaborados por Giovani José da Silva (2000) e por Gabriel Ulian (2013), ambos em Antropologia. Sobre os Atikum em Pernambuco, os textos de Grünewald (1993, 2004) seguem sendo as mais importantes referências, ao lado da dissertação de mestrado de Georgia da Silva (2007). A diáspora Atikum não se limita, porém, às terras sul-mato-grossenses, encontrando-se hoje nos estados do Pará e da Bahia. Em 2018, após decisão judicial, os caboclos da Serra do Umã conquistaram o direito de ocupar uma porção de terras no município de Nioaque, onde já vivem há, pelo menos, 35 anos. Um longo percurso os aguarda, porém, até que estejam sobre a terra indígena 
Atikum, alimentando histórias e memórias, impulsionados pelos "encantos de luz"5. Tal situação é bastante distinta daquela vivida pelos indígenas Kamba.

Os Kamba, ou Camba-Chiquitano (autodenominação do grupo), figuram na relação das sociedades indígenas que vivem hoje no estado de Mato Grosso do Sul há algum tempo (MANGOLIM, 1993), embora existam poucos estudos recentes que se refiram especificamente a eles (R. H. SILVA, 2009; JOSÉ DA SILVA, 2012). Desqualificados regionalmente como "índios sem-terra”, "bolivianos”, “campesinos” ou, ainda, "bugres”, o que chama a atenção é que se discutiu muito, até hoje, se eles são indígenas de fato. A antropóloga Yara Maria Brum Penteado (1980) defendeu a dissertação de mestrado intitulada A condição urbana: estudo de dois casos de inserção do índio na vida citadina na Universidade de Brasília (UnB), sob a orientação de Júlio Cezar Melatti, a respeito desses indígenas.

No texto da dissertação, a autora se refere, além dos Terena, aos CambaChiquitano, denominados “Kamba” ou "Camba". Entretanto, a particular e complexa trajetória histórica dos primeiros indígenas que chegaram a Corumbá, e de seus atuais descendentes, tanto do lado brasileiro quanto do lado boliviano, ainda era desconhecida e merecia estudos de maior profundidade. A pesquisa de Penteado (1980) se desenvolveu no final da década de 1970 e, a princípio, foi solicitada pela Funai, resultado do II Encontro da Pastoral Indigenista de Mato Grosso, ocorrido em agosto de 1978 em Aquidauana-MS. A própria autora revelou surpresa com o pedido do órgão indigenista, "uma vez que os índios em questão não eram aldeados, nem eram sequer brasileiros" (PENTEADO, 1980, p. 53).

Na época em que os pesquisou, Penteado (1980) concluiu que os Kamba eram de origem boliviana, viviam em condição de extrema miséria, se autoidentificavam e eram identificados como indígenas. Ainda de acordo com a antropóloga, "essa condição lhes proporcionava uma visível discriminação por parte de seus vizinhos (embora também

\footnotetext{
${ }^{5}$ De acordo com a fala de um indígena Pankararé, recolhida por Maria Rosário G. de Carvalho (1984, p. 182), "encantado [encanto de luz] é o espírito do índio que volta". Entre os Atikum de Mato Grosso do Sul, os "encantados" são invocados sempre que se realiza entre eles o ritual do Toré. Inclusive, atualmente, afirmam que o senhor Aliano Vicente sempre retorna à aldeia, desde que partiu, para compartilhar a dança com os seus, pois se tornou um “encanto de luz" (JOSÉ DA SILVA, 2019).
} 
fossem bolivianos em sua maioria) - demonstrada, dentre outras formas, pelo vocativo de conotação pejorativa: “Bugres”” (PENTEADO, 1980, p. 54). Justamente para dirimir dúvidas quanto à "indianidade" dos Kamba, alguns trabalhos técnicos foram produzidos pela Funai a respeito dessa sociedade indígena, entre o final dos anos 1970 e o início dos anos 1980. O processo de regularização da terra indígena Kamba, porém, encontra-se paralisado pela Funai desde 1987, apesar dos pareceres terem apontado a legitimidade da reivindicação dos indígenas.

Além dos trabalhos de Yara Penteado, dois pesquisadores realizaram estudos acadêmicos sobre os Kamba: Giovani José da Silva (2009), em doutorado no Programa de Pós-Graduação em História da Universidade Federal de Goiás (UFG); e Ruth Henrique da Silva (2009), doutora pelo Programa de Pós-Graduação em Antropologia da Universidade Federal Fluminense (UFF). Com a morte recente do senhor Nazario Surubi Rojas, reconhecida liderança entre os Kamba, as reivindicações arrefeceram e o processo de luta pela terra se encontra suspenso. Apesar disso, os indígenas continuam a viver em Corumbá, na periferia da sede do município, localizado na fronteira Brasil-Bolívia, onde constituíram uma aldeia - nos moldes de uma antiga missão jesuítica -, no mesmo local que servia como lixão da cidade no passado. Ali, com muitas dificuldades, o grupo vive e reproduz-se desde meados da década de 1950. Como se vê a seguir, as diásporas Atikum e Kamba se realizaram ao longo da segunda metade do século XX e foram marcadas pelo deslocamento dos grupos em busca de melhores condições de vida, diferentemente do que ocorreu com os Kinikinau.

Dados como extintos a partir da segunda metade do século XX, os Kinikinau iniciaram uma intensa mobilização sociopolítica no final dos anos 1990, ainda em curso, reivindicando uma etnicidade própria e distinta dos indígenas Terena, com quem foram confundidos durante muito tempo e de quem são parentes linguísticos e culturais. Um dos sinais diacríticos utilizados pelo grupo para se autoafirmar Koinukunôen (autodenominação) é a produção de cerâmica, inspirada na conhecida cerâmica Kadiwéu. Os Kinikinau vivem distribuídos em algumas aldeias Terena dos municípios sul-matogrossenses de Aquidauana, Miranda, Nioaque, dentre outros, e concentravam-se, até o 
ano de 2016, em terras da aldeia São João (distante cerca de 70 km de Bonito-MS), uma das 6 aldeias que atualmente compõem a Reserva Indígena Kadiwéu.

A histórica diáspora dos Kinikinau merece estudos mais aprofundados e ainda está por ser desvelada ${ }^{6}$. Preliminarmente, a pesquisa em escritos produzidos por cronistas, viajantes e exploradores do período colonial luso-brasileiro permite inferir que 4 subgrupos Guaná atravessaram o Rio Paraguai, passando para suas margens orientais: a) Exoaladi; b) Terena; c) Layana; e d) Kinikinau. Destes, apenas os primeiros não apresentam, até o momento, descendentes autodeclarados no atual território sul-matogrossense. Tais grupos teriam atravessado o Rio Paraguai em ondas sucessivas a partir da segunda metade do século XVIII, instalando-se na região banhada pelo Rio Miranda, entre os paralelos $19^{\circ}$ e $21^{\circ}$ de Latitude Sul, onde foram encontrados por não indígenas no século XIX. Os Exoaladi, segundo o antropólogo Roberto Cardoso de Oliveira (1976), teriam desaparecido por ocasião da Guerra do Paraguai. Os Terena compõem o grupo de maior expressão dentre os remanescentes dos antigos Guaná na atualidade e os Layana vivem dispersos em aldeias Terena dos municípios de Aquidauana e Miranda.

Os Kinikinau, por sua vez, teriam ficado “ocultos” em meio ao grupo majoritário Terena e entre o final do século XIX e o início do século XX foram pouco mencionados em documentos escritos. Tornou-se "natural" se referir a eles como um subgrupo Terena, especialmente após a destruição do último aldeamento reconhecidamente pertencente ao grupo, localizado próximo à região do Rio Miranda, por volta de 1910.

Sobre o processo de "extinção" do grupo e ainda de acordo com Cardoso de Oliveira (1976, p. 27):

Dentre as inúmeras tribos ou subtribos a desaparecerem ainda no presente século $[X X]$, podemos apontar os Kinikináu (Guaná) e os OfaiéXavante. Os primeiros mantinham ainda uma aldeia, junto ao [R]io Agaxi, de onde se dispersaram, expulsos de suas terras por um civilizado que as teria comprado do Estado do Mato Grosso; seus remanescentes são encontrados hoje em algumas aldeias Terena.

\footnotetext{
${ }^{6}$ O pesquisador João Filipe Domingues Brasil vem realizando, desde 2018, pesquisas para o Doutorado em História na Universidade Salgado de Oliveira (Universo), sob a orientação de Márcia Amantino, a respeito das redes de relações dos Kinikinau com indígenas e não indígenas na passagem dos séculos XVIII e XIX.
} 
Durante muito tempo foi negada aos Koinukunôen pelo próprio órgão indigenista, primeiro o Serviço de Proteção aos Índios (SPI) e depois a Funai, a possibilidade de identificarem-se como Kinikinau, pois eram obrigados pelos chefes de posto e outros funcionários a se registrarem como Terena. Dessa forma, identificar-se como Terena representou, durante muito tempo, uma das estratégias utilizadas pelo grupo Kinikinau para sobreviver a toda sorte de perseguições a que foi submetido. Hoje, a "vontade de diferença" se revela na fabricação de cerâmica pelas mulheres, dentre outras práticas culturais (JOSÉ DA SILVA; SOUZA, 2008). Os Kinikinau não desejam ser Kadiwéu por terem habitado terras desses índios e muito menos Terena, de quem estão próximos cultural e linguisticamente, oriundos do mesmo grande grupo Guaná/Chané no passado.

Atualmente, os Kinikinau vivem, sobretudo, de atividades agrícolas e artesanais. Os mais velhos ainda falam cotidianamente a língua, filiada à família linguística Aruak, e a maioria, composta por crianças, jovens e adultos, comunica-se apenas em língua portuguesa. A autodenominação do grupo é Koinukunôen, que em seu idioma materno quer dizer "índio guerreiro", em contraposição a uma identidade Terena impingida a eles através dos tempos. Há notícias de membros desse grupo residindo também em terras dos Terena, nas aldeias Bananal, Limão Verde (Aquidauana), Cachoeirinha, Lalima (Miranda), Água Branca, Taboquinha, Cabeceira e Brejão (Nioaque), dentre outras. Além disso, há uma parte do grupo nas chamadas "retomadas" de terras, entre Aquidauana e Miranda, lutando por territórios outrora ocupados pelos ancestrais.

Recentemente, uma coletânea a respeito do grupo foi lançada, sob o título Kinikinau: arte, história, memória \& resistência (JOSÉ DA SILVA; BOLZAN; SOUZA, 2017) e há até o momento somente um trabalho na área de História, a dissertação de mestrado Cerâmica Kinikinau: a arte de um povo tido como extinto, de Lucicleide Gomes dos Santos (2011). A escassez de trabalhos sobre os "ressurgidos" ou "emergentes" Kinikinau - e, também, sobre os Kamba e os Atikum - pode estar relacionada, dentre outros fatores, à falta de visibilidade desses e de outros grupos (Layana, Chamacoco e Ayoreo), bem como à ausência de evidentes sinais diacríticos, os sinais da diferença étnica e cultural. A utilização de nomenclaturas tais como "ressurgidos" e “emergentes”, no entanto, não dá conta das novas realidades encontradas nas aldeias e nas cidades brasileiras, construídas 
a partir de diásporas, multiterritorialidades, desterritorializações/reterritorializações e lutas indígenas.

\section{"Ressurgidos", “emergentes”, "resistentes": (re)pensando nomenclaturas a partir dos Kinikinau}

A ideia de tratar grupos indígenas, tais como os Atikum, os Kamba e/ou os Kinikinau como "ressurgidos" ou "emergentes" desagrada aos próprios indígenas. Segundo muitos deles, tais expressões mascaram a dura realidade a que foram submetidos ao longo do tempo, tentando sobreviver a toda sorte de dificuldades. As expressões "ressurgidos" e/ou "emergentes" carregariam a noção de que determinadas populações teriam "desaparecido" e que, no final do século XX e início do século XXI, estariam "ressurgindo" ou “emergindo", em um processo de "geração espontânea"! Nada mais falso, quando se verifica, por exemplo, as trajetórias históricas e diaspóricas dos Kinikinau, dentro e fora das atuais terras sul-mato-grossenses. Por tal razão, esse e outros grupos indígenas têm adotado a expressão "resistentes" em diversas falas e documentos oficiais que têm divulgado nos últimos anos, nos encontros promovidos por organizações governamentais e não governamentais (indígenas e indigenistas).

Segundo Giovani José da Silva e José Luiz de Souza (2003, p. 155):

Os Kinikinau, assim como membros de outras sociedades indígenas do Brasil de hoje, não desejam ser chamados de "ressurgidos", pois entendem que a conotação seja pejorativa e pouco explicativa da situação histórica a que foram submetidos. Preferem, por essa razão, a expressão "resistentes".

De acordo com lideranças Kinikinau, ouvidas durante trabalhos de campo, a palavra "resistente" expressaria a ideia de que essas populações sempre estiveram presentes, ainda que ocultas, e enfrentaram os processos de colonização e de desterritorialização. Historicamente, há uma ideia de continuidade por trás da expressão "resistente", estrategicamente utilizada pelos grupos na afirmação de suas respectivas identidades étnicas e culturais. As sobrevivências dos Atikum, Kamba e Kinikinau, em meio ao desaparecimento de mais de 80 etnias, somente na primeira metade do século 
XX (RIBEIRO, 1970), demonstram a força do que pode ser chamado de "lugares do não esquecimento" (JOSÉ DA SILVA, 2007). Os Kinikinau e tantos outros grupos indígenas da contemporaneidade, tais como os Kaxixó (Minas Gerais) e os Tupinambá (Bahia), desejam não esquecer o que são nem o que foram no passado, projetando - em narrativas orais e performances - perspectivas do que desejam ser no tempo presente.

Por essa razão, mesmo que ainda não tenham porções de terras identificadas, delimitadas, demarcadas e homologadas pelo órgão indigenista oficial, os caboclos da Serra do Umã (Atikum), os Camba-Chiquitano (Kamba) e os Koinukunôen (Kinikinau) se fazem e refazem indígenas cotidianamente, reterritorializando-se nos campos e nas cidades de Mato Grosso do Sul. Se ainda não há espaços físicos, criam-se lugares simbólicos, "lugares do não esquecimento", territorialidades que se constroem por meio da memória social, resistindo às tentativas de extermínio, às políticas públicas promotoras de invisibilidade, ao silêncio acadêmico, à indiferença de outros indígenas e de não indígenas. A luta pelos espaços físicos, porém, é necessária e urgente, uma vez que sem terras e sem territórios se tornam frágeis os suportes das identidades étnicas e culturais, provocando fissuras e rasgos no tecido social, obrigando à dispersão e ao abandono forçado de pautas culturais, línguas e representações próprias.

A resistência pode ser pensada a partir dos pressupostos da interculturalidade crítica, teorizada por Catherine Walsh (2009) e outros intelectuais decoloniais. Questionando continuamente a racialização, a subalternização, a inferiorização e seus padrões de poder, a interculturalidade crítica visibiliza maneiras diferentes de ser, viver e saber. Além disso, busca o desenvolvimento de "modos outros", constituindo-se em alicerce, ao lado da decolonialidade, de projetos, processos e lutas da chamada (re)existência. A interculturalidade crítica difere da chamada interculturalidade funcional, pois esta última estaria interessada apenas em promover o diálogo e a tolerância sem tocar nas causas das assimetrias sociais e culturais entre indígenas e não indígenas, por exemplo (WALSH, 2009). Dessa forma, por meio da interculturalidade crítica é possível perceber as territorialidades (re)criadas pelos indígenas Atikum em Mato Grosso do Sul, por exemplo, e suas lutas por resistir e (re)existir longe de “casa”. 


\section{Terras e territórios indígenas: (re)vendo conceitos a partir dos Atikum}

Para o estudo das trajetórias diaspóricas das populações indígenas Atikum, Kamba e Kinikinau em Mato Grosso do Sul, as reflexões a partir da noção de território e de “viagem da volta”, desenvolvidas pelo antropólogo João Pacheco de Oliveira (1998, 2004), auxiliam na elucidação sobre terras e territórios indígenas. Segundo o autor, o território indígena não se define somente por critérios históricos, mas, também e principalmente, por critérios culturais próprios dos grupos que o habitam, sendo mapeado a partir das necessidades de sobrevivência do grupo, entendida em sentido amplo e não simplesmente material. Disso resulta que o conceito de território pode ser aplicado em aspecto duplo: como meio básico de produção e, também, sustentáculo das identidades étnica e cultural. Contudo, a dimensão territorial (com toda a polissemia característica do termo território) não se sustenta somente pelas noções ou conceitos de “terras" e "territórios", mas também pelas noções de territorialização, territorialidade, multiterritorialidade e desterritorialização/reterritorialização, levando-se em conta a “viagem da volta", que nem sempre é física.

Concorda-se, pois, com Claude Raffestin (1993), para quem a territorialidade é mais do que uma simples relação homem/território. O geógrafo argumenta que, além da demarcação de parcelas individuais, também existem as relações sociais entre os indivíduos e entre os grupos. Dessa forma, a territorialidade seria "um conjunto de relações que se originam num sistema tridimensional sociedade-espaço-tempo em vias de atingir a maior autonomia possível, compatível com os recursos do sistema" (RAFFESTIN, 1993, p. 160). Assim, é necessário tentar definir a importância da dimensão territorial para a constituição das identidades Atikum, Kamba e Kinikinau, objetivando compreender por meio de quais categorias ou representações os indígenas pensaram/sentiram/viveram/representaram suas territorialidades, ao longo do tempo, e quais instrumentos têm utilizado para manter sua unidade e seu controle.

No caso Atikum, em que parte do grupo se viu forçada a um deslocamento que levou os indígenas para longe de seu território tradicional, o conceito de territorialização é útil por reafirmar que “enquanto 'espaço-tempo vivido', o território é sempre múltiplo, 'diverso e complexo', ao contrário do território 'unifuncional' proposto pela lógica 
capitalista hegemônica" (HAESBAERT, 2004, p. 2). Os antropólogos Anthony Seeger e Eduardo B. Viveiros de Castro (1979), em texto intitulado Terras e territórios indígenas no Brasil, ao realizarem uma análise de como as mudanças na relação com a terra consequências da dominação e contato com a sociedade envolvente -, afetam a organização social e a definição étnica dos diferentes grupos indígenas, sublinham a diferença entre um conceito de terra como meio de produção, lugar do trabalho agrícola ou solo onde se distribuem recursos animais e de coleta, e um conceito de território “tribal”, de dimensões sócio-político-cosmológicas mais amplas. No caso Atikum há uma percepção de que existem conflitos entre o que são terras indígenas por parte da sociedade nacional e o uso que eles próprios fazem delas, mesmo que temporariamente sejam "alheias", construindo territorialidades para sua própria definição e contrastando com a sociedade não indígena.

William Balée (2008), ao propor discussões sobre "indigeneidade das paisagens" auxilia na compreensão e na análise das relações estabelecidas pelas populações indígenas com suas territorialidades. Na concepção das diversas sociedades indígenas brasileiras - e com os Atikum de Mato Grosso do Sul não é diferente -, o território é um “mosaico" de recursos materiais, morais e espirituais, pois suas terras, além de conterem dimensões sociopolíticas, têm uma ampla dimensão cosmológica. A "Indigeneidade se refere às maneiras tradicionais de conhecimento do mundo, imersas em culturas de pequena escala" (BALÉE, 2008, p. 9), e, dessa forma, pode-se afirmar que a indigeneidade da paisagem Atikum, em terras sul-mato-grossenses, é detectada nas transformações primárias da paisagem, onde, por exemplo, roças de milho, feijão, abóbora etc. resultaram em melhorias ambientais, não em degradação da terra indígena Terena, em Nioaque. Se paisagens são encontros de pessoas e lugares, como também sugere Balée (2008), os Atikum (re)criaram a Serra do Umã em “terra alheia”, em terras Terena.

Em um estudo sobre território e territorialidades indígenas do Alto Rio Negro, no estado do Amazonas, a geógrafa Ivani Ferreira de Faria (2003) recolheu algumas narrativas que dão pistas sobre a dimensão do que significam terras e territórios para determinados grupos indígenas daquela região do país.

Braz França, da etnia Baré, assim se exprimiu à pesquisadora: 
A demarcação da terra contínua significa para os índios o futuro de suas gerações. Por que nós estamos lutando por isto? [...] Porque nós percebemos que estamos perdendo espaço dentro da nossa própria terra com invasões, grandes projetos econômicos e penetração de políticos e empresários. [...] nós vivemos na terra, andamos na terra, usamos a terra. A terra é atividade cultural, ritual, para outros tipos de sobrevivência. [...] o índio sobrevive da terra. A terra é quem dá sustentação. Por isto é preciso ampliar, é preciso que a terra seja suficiente para manter esta sobrevivência (FARIA, 2003, p. 97-98).

Outro entrevistado, Gersem Santos, da etnia Baniwa, diferenciando terra e território, afirmou a Faria (2003, p. 105-106) que:

[...] na concepção tradicional, original, não existia o termo território. Não teria sentido discutir isso. O sentido de território só existe após o contato. Antes do contato, o índio podia ir e vir, ele definia sua própria vida, seu destino sem tutela, sem nada e sem pré-condições. [...] Depois do contato há pré-condições. Estas são impostas pela dominação, exploração, pela violência. E você precisa afirmar-se. Antes não, a natureza te garante isto. A terra te garante isto. Por isto terra é tudo. Depois a terra já não é tudo. Você precisa de elementos políticos. Aí você tem um conceito de território, que tem sentido de poder, sentido de domínio e de limite. Território é limite. É você limitar o espaço. A terra é uma coisa ilimitada; ilimitável. Ela é tudo. Como você vai considerar limite numa concepção ilimitada de terra que seria o território! Não tem como fazer a relação. Só é possível pensar o território depois do contato porque você limita as coisas.

É a partir das falas dos indígenas Gersem Baniwa e Braz Baré - e concordando-se com o antropólogo Roberto Balza Alarcón (2001) - que se define o território como todo espaço que é atualmente imprescindível para que um grupo indígena tenha acesso aos recursos naturais que tornem possível sua reprodução material e espiritual, de acordo com características próprias de organização produtiva e social. Esse espaço pode apresentar-se, ainda, de maneira contínua ou descontínua. Assim, o conceito jurídico de terra, que se refere somente ao espaço geográfico que tem sido fixado para uma comunidade ou pessoa em função de critérios exclusivamente agrários, não contempla os sistemas produtivo e sociocultural de um grupo indígena, ainda que seja útil para que este efetue, parcialmente, as atividades referidas àqueles âmbitos.

Por essa razão, os Atikum vêm lutando, pelo menos desde 2005, junto à Procuradoria da República em Mato Grosso do Sul (PR/MS), quando enviaram uma carta relatando os problemas enfrentados desde meados da década de 1980 , solicitando que 
uma providência urgente fosse tomada em relação à identificação, delimitação, demarcação e homologação de terras para o grupo. Desterritorializados, migrantes e sofrendo dupla discriminação, por se afirmarem indígenas e, ao mesmo tempo, serem vistos/considerados "negros quilombolas": eis a situação vivida pelos caboclos ao longo dos últimos 35 anos no estado. Juridicamente, as terras indígenas recebem tipificações, de acordo com o Direito Fundiário, sendo que as terras a serem adquiridas pela União para os Atikum podem ser enquadradas nas de tipo “dominiais”, que são aquelas "recebidas pelos índios em virtude de ações do [D]ireito [C]ivil, como a doação compra e venda ou permuta" (TOURINHO NETO, 1993, p. 40).

Os Atikum aguardam com expectativa a resolução dos problemas relacionados à falta de terras em Mato Grosso do Sul, onde possam reterritorializar-se, realizando o ritual do Toré, sem serem importunados e onde não sejam mais conhecidos por apelidos de caráter depreciativo. "Terra seca" é um nome criado de fora para dentro do grupo, que tenta desqualificá-los, enquanto oriundos de um lugar desprovido de água e de difícil sobrevivência. É uma representação do grupo hegemônico, no caso os Terena, que lhes impingiu a alcunha. É interessante notar que aquilo que os Atikum de Mato Grosso do Sul menos têm é terra, só aparecendo nos nomes pejorativos que lhes deram. As terras da aldeia Cabeceira cedidas aos Atikum correspondem a cerca de 60 hectares da terra indígena de Nioaque. Estão "fracas", como dizia Aliano Vicente, e dela não se pode retirar nada além de uma roça de subsistência (mandioca, abóbora, feijão etc.). A água para consumo, plantações e gado é obtida por meio de poços perfurados, pois não há rios próximos. Como se pôde verificar, não é somente em Pernambuco que a terra é seca e as condições são difíceis. Apesar disso, o líder Atikum manteve esperanças, enquanto vivo, em uma mudança favorável da situação em que viviam os caboclos:

A dificuldade é grande, eu já tenho caçado posição pra ajudar, pedi ajuda pra Funai, pra criarmos condições. Eu tenho ficado aqui uns dois, três anos sem trabaiá, e a terra é fraca, inclusive agora já tô completando quatro ano tô aí parado nessa área que nós sabemo que não produz nada. Foi essa área que os Terena colocaram nós prá trabalhar, tem muitos que vão procurar serviço na fazenda, mas eu ainda tenho muita fé em Deus que ainda vai havê uma melhora (JOSÉ DA SILVA, 2019, p. 4849). 
Sempre que falava sobre terras e a possibilidade de ocupar um lugar para chamar de território indígena Atikum, oficialmente reconhecido, Aliano José Vicente rememorava os tempos em que vivia em Pernambuco. Afinal, um assunto do qual os Atikum gostam e fazem questão de falar é sobre a Serra do Umã, o lugar que deu origem a Atikum e a toda a comunidade indígena. Além da falta d'água, que trazia recordações cheias de dor e sofrimento, outro ingrediente dessas lembranças era o Toré, ritual comum a vários povos indígenas do Nordeste. Em Pernambuco, era realizado em um terreiro próprio para isso e dele participavam centenas de pessoas, sob o comando do pajé. Em Nioaque não se verificou a presença de pajé e quem conduzia o ritual era o próprio Aliano, auxiliado pelos filhos, hoje os responsáveis pela manutenção das tradições Atikum:

O tempo que eu saí de lá [Pernambuco] ele [Arcindo] era o pajé, ele que ensaiava o Toré lá no terreiro, a gente cantando e dançando: tinha um cruzeiro muito grande de aroeira lá no terreiro que a gente brincava. Naquele terreiro eles fizeram uma oca, que é o local deles colocá a lamparina que é prá alumiá o terreiro onde a gente vai brincar, aquela coisa é importante (JOSÉ DA SILVA, 2019, p. 49).

O Toré é uma dança realizada com os participantes perfilados, em círculos no terreiro, mas não há uma regra rígida para os movimentos, ora sendo realizados em sentido horário e depois no sentido inverso. Um "puxador de linha", aquele que determina qual é o "toante" (música curta de caráter laudatório) a ser executado, vai à frente cantando e animando os demais, além de distribuir os dançarinos pelo terreiro. Às crianças é permitida a participação, até mesmo aos pequeninos. Cada participante segura nas mãos um chocalho e o ritmo da dança é dado pelas batidas dos pés. O resultado é harmonioso e, ao terminar cada linha de Toré, cabe ao puxador reunir os participantes em círculo no centro do terreiro, com os chocalhos balançando ao alto, para proferir alguns agradecimentos.

Em trabalhos de campo realizados no início dos anos 2010, Gabriel Ulian (2013) recolheu um "toante" relacionado à forma como os Atikum de Mato Grosso do Sul concebem sua territorialidade. Ao cantarem "Eu ando em terra alheia, procurando minha aldeia", os caboclos deixavam claro que apesar de sentirem-se "estrangeiros" em terras Terena, nutriam sentimentos de esperança de encontrarem a própria aldeia, um lugar para chamar de "casa”. Aliano Vicente dizia que sua mãe, a terra (Serra do Umã), não 
tinha "leite" para amamentar a todos os filhos, por isso havia saído de lá, de perto dela. Ao chegar a Mato Grosso do Sul, depois de passar por inúmeras vicissitudades nos deslocamentos, ao lado de outros indígenas como ele, pediu as "tetas" emprestadas da "mãe terra" dos Terena, mas ela também estava fraca e não podia alimentar a todos os caboclos, daí a necessidade de um território próprio.

A memória do velho Atikum se apresentava como um repositório de informações, sensações, lembranças de tempos de outrora, reconstruções elaboradas no tempo presente. Ainda que um indivíduo seja o portador dessas lembranças, no caso o senhor Aliano, é possível inferir ideias e representações de um grupo, como os Atikum, pois se pode considerá-lo como um homem-memória, um especialista da memória em sociedades sem escrita (LE GOFF, 1992). Afinal, as memórias são construções de grupos sociais, ou seja, os indivíduos lembram no sentido físico, mas são os grupos dos quais fazem parte que determinam o que é importante ser rememorado/esquecido e de que forma será narrado. Entre os Kamba, moradores de uma aldeia localizada em zona urbana na periferia da cidade de Corumbá, fronteira Brasil-Bolívia, também foi encontrado um homem-memória, durante os trabalhos de campo realizados entre 2005 e 2009, o senhor Nazario Surubi Rojas.

\section{Memória social: (re)construindo territorialidades com os Kamba}

Para Michael Pollack (1992, p. 204), há, entre a memória e o sentimento de identidade, a autoimagem "que uma pessoa adquire ao longo da vida [...] que constrói e apresenta aos outros e a si própria, para acreditar na sua própria representação, mas também para ser percebida da maneira como quer ser percebida pelos outros". Os encontros com o senhor Nazario Rojas (Nazário Rocha, em seus documentos de “brasileiro") foram marcados por essa perspectiva e ensejaram reflexões sobre como

[...] a memória é um elemento constituinte do sentimento de identidade, tanto individual como coletiva, na medida em que ela é também um fator extremamente muito importante do sentimento de continuidade e de coerência de uma pessoa ou de um grupo em sua reconstrução de si (POLLACK, 1992, p. 204, grifo do autor). 
A contínua reconstrução da memória corresponde, portanto, à contínua reconstrução do sentimento de identidade. Oriundos da Bolívia, os Camba-Chiquitano mais idosos, como o senhor Nazario Rojas, fizeram questão de registrar suas memórias, a fim de que não se perdessem para sempre na poeira do tempo ou que fossem esquecidas em algum "lixão". Presentes no Brasil há mais de 50 anos, os indígenas migrantes refizeram em Corumbá um pueblito, evocando lembranças dos "tempos de antigamente", em que seus ancestrais habitavam as "terras baixas" (tierras bajas) bolivianas, próximos às antigas missões jesuíticas de Chiquitos. Foi na paisagem do Oriente boliviano que se fizeram indígenas e continuaram a sê-lo, mesmo depois que vieram para o Brasil, ao se reterritorializarem, transformando a paisagem com sua "indigeneidade".

Uma vez em terras brasileiras, os Camba-Chiquitano recriaram uma espécie de povoado no bairro "Cristo Redentor", buscando reproduzir, parcialmente, em termos de práticas ambientais e culturais, uma parcialidade da paisagem deixada para trás, nos "tempos dos antigos". Assim, a ocupação do que viria a ser o "Reduto São Francisco de Assis" ou "Alameda" constituiu momento fundamental para a história coletiva do grupo: tratava-se do "lixão" da cidade, onde não cresciam plantas, por conta dos resíduos deixados pelas mineradoras locais (principalmente manganês, de acordo com os moradores do local), um ambiente insalubre e inóspito. Domesticar tal paisagem, transformando-a em território culturalmente efetivo - lócus de relações sociais e de reprodução cultural e física - também foi o momento embrionário de uma identidade exclusiva, a de Camba-Chiquitano, conectada aos Chiquitanos, mas em parte diferente daquela que havia sido abandonada na Bolívia (JOSÉ DA SILVA, 2015).

A memória social, como a individual, é seletiva e flexível, e é preciso identificar os princípios de seleção e flexibilidade e como ocorrem mudanças nestes, com o passar do tempo. Quais são os modos de transmissão de lembranças entre os Kamba - além dos Atikum e dos Kinikinau - a respeito de suas territorialidades? De modo inverso, quais são os usos do esquecimento entre esses grupos indígenas? O que o presente não solicita à memória é esquecido, pois "as fronteiras desses silêncios e 'não ditos' com o esquecimento definitivo e o reprimido inconsciente [...] estão em perpétuo 
deslocamento" (POLLACK, 1989, p. 8). O rememorar também é estimulado pelos lugares, testemunhos atuais de acontecimentos passados, de personagens e relações pessoais. $A$ memória individual, portanto, é, em parte, herdada, e, assim como a coletiva, é social (MANCUSO, 2000).

Em relação às sociedades indígenas, os princípios, pressupostos e símbolos da memória estão intimamente relacionados às territorialidades desenvolvidas por cada grupo. Assim, ainda que não ocupem atualmente terras identificadas, delimitadas, demarcadas e/ou homologadas em Mato Grosso do Sul, os Atikum, os Kamba e os Kinikinau criaram representações simbólicas sobre o viver em uma "aldeia" e o "ser índio". Seja na (às vezes) difícil convivência com os Terena e com os não indígenas - caso dos Atikum; seja enfrentando os preconceitos contra estrangeiros, como vêm fazendo bravamente os Kamba, a reprodução física e cultural dos indígenas encontra caminhos e dribla dificuldades, mesmo que assumindo forçadamente a identidade étnica de outro grupo - caso dos Kinikinau. A histórica concentração fundiária em todo o Brasil e, particularmente, em Mato Grosso do Sul, nas mãos de poucas famílias não indígenas, obriga os indígenas a renovadas estratégias e táticas de sobrevivência, de resistências e de (re)existências (WALSH, 2009). Além disso, a falta ou a diminuta produção de trabalhos acadêmicos que auxiliem a compreensão histórica dessas presenças e de suas trajetórias diaspóricas precisa ser revista com urgência, em um momento histórico no qual são constantes as ameaças aos indígenas e aos seus direitos no Brasil.

\section{Conclusões}

O historiador Pierre Nora (1993, p. 13) assim se exprime sobre o que denominou "lugares de memória":

Os lugares de memória nascem e vivem do sentimento que não há memória espontânea, que é preciso criar arquivos, que é preciso manter aniversários, organizar celebrações, pronunciar elogios fúnebres, notariar atas, porque essas operações não são naturais. É por isso a defesa, pelas minorias, de uma memória refugiada sobre focos privilegiados e enciumadamente guardados nada mais faz do que levar à incandescência a verdade de todos os lugares de memória. 
Sobreviver a todo o custo foi o que fizeram indígenas das etnias Atikum, Kamba e Kinikinau, dentre outras tantas, hoje mais de 250 (BRASIL, 2010), distribuídas por todo o país. Essa sobrevivência significou, também, organizar celebrações, mesmo quando estavam sob perseguição ou proibidos de revelar quem eram. Entretanto, os laços de pertencimento ao grupo étnico e as práticas culturais mantidas permitiram não apenas a sobrevivência física, mas, especialmente, a sociocultural. Os indivíduos pertencentes a essas sociedades não desejaram esquecer quem eram/foram e hoje lutam contra o preconceito e a discriminação, transformando estigmas em marcas de positividade (ANDRADE, 2004). Esse preconceito não é apenas daqueles que estiveram longe dos bancos escolares, mas, também, de pesquisadores e professores que enxergam indígenas como os Atikum, por exemplo, como "menos índios" ou "aculturados", porque estes não apresentam determinado grau de contrastividade em relação aos não indígenas.

Pode-se dizer que, assim como os Kalancó, em Alagoas, estudados pelo antropólogo Ugo Maia Andrade (2004, p. 110), os Atikum, os Kamba e os Kinikinau “constituem um coletivo formado a partir de um processo de diáspora". E, da mesma forma como ocorreu com aqueles indígenas no Nordeste brasileiro, houve a estigmatização dos grupos em Mato Grosso do Sul, aos quais foram atribuídas representações negativas, especialmente ligadas à falta de terras e à ausência de fortes sinais diacríticos, as marcas da diferença étnica e cultural. Com o tempo, porém, categorizações pejorativas ("terra seca”, “índios sem-terra”, “bugres”, "bolivianos”, “Terena”) dirigidas pela população não indígena regional/local foram sendo neutralizadas e transformadas em atributos positivos de identidade, ao se modificar valores que a elas estavam agregados. Nas palavras de Andrade (2004, p. 115), inspirado em Pierre Bourdieu, isso significa "transformar um estigma em emblema de identidade", ou seja, a modificação dos sinais dos estigmas externamente imputados e a alteração do quadro de forças atuantes em determinado social, compreendendo-se as territorialidades, além das culturas, como um dos meios instrumentais por meio dos quais os indígenas outrora estigmatizados se redefiniram e se redefinem continuamente diante de outras forças sociais, (re)existindo. 
Assim é que os Atikum, os Kamba e os Kinikinau, oriundos de diferentes lugares e hoje presentes em Mato Grosso do Sul, fizeram-se indígenas e continuam a se fazer cotidianamente, a despeito dos estigmas e estereótipos construídos pelo entorno. Sem portarias declaratórias (documento do Ministério da Justiça que declara a posse permanente de um grupo indígena sobre determinadas terras), expedidas pelo órgão indigenista oficial, que lhes garantam o usufruto de territórios físicos para habitarem e reproduzirem-se, elaboraram territorialidades (ou melhor, multiterritorialidades) ao longo do tempo, ainda que estivessem sempre, na condição de grupos diaspóricos, entre duas lealdades: a da "casa" ou da "mãe" deixada e a do novo lugar escolhido para a (re)invenção de tradições e (re)existências indígenas. As territorialidades constituídas nesses processos só foram possíveis pela presença de homens e mulheres-memória (como dona Zeferina Kinikinau), guardiães dos saberes e fazeres, da "indigeneidade" dos grupos.

Antropólogos, historiadores e outros estudiosos que pesquisam sociedades indígenas precisam de novas palavras para explicar novas realidades ligadas a fenômenos que têm marcado o tempo presente, tais como a resistência de identidades étnicas e as (re)existências múltiplas e plurais marcadas por trajetórias diaspóricas. Por isso, ao invés de falar-se em "lugares de memória", como sugere Nora, prefere-se a expressão "lugares do não esquecimento", multiterritorialidades em deslocamentos constantes, frutos de negociações, táticas e estratégias de sobrevivências físicas, culturais, sociais, espirituais. Tais territorialidades podem fazer-se em uma "aparente favela" (Kamba), em "terra alheia" (Atikum) ou em uma "retomada" (Kinikinau). Esses seriam alguns dos lugares ocupados hoje pelos indígenas Atikum, Kamba e Kinikinau, povos desterritorializados e que buscam reterritorializar-se, seja "perto" ou "longe" de "casa". Tais "territórios" são locais não apenas físicos, mas, também (e principalmente) simbólicos, territorialidades construídas e reconstruídas por meio da memória social, através dos tempos, dentro e fora do atual estado de Mato Grosso do Sul, "onde um boi vale mais que uma criança indígena" (SANSON, 2014). 


\section{Referências}

ANDRADE, Ugo Maia. Dos estigmas aos emblemas de identidade: os percursos da formação de um povo. Revista de Estudos e Pesquisas, Brasília, v. 1, n. 1, p. 99-139, 2004.

BALÉE, William. Sobre a indigeneidade das paisagens. Revista de Arqueologia, Juiz de Fora, v. 21, n. 2, p. 9-23, 2008.

BALZA ALARCÓN, Roberto. Tierra, territorio y territorialidad indígena: un estudio antropológico sobre la evolución en las formas de ocupación del espacio del pueblo indígena chiquitano de la ex-reducción jesuita de San José. Santa Cruz de la Sierra, Bolivia: APCOB/SNV/IWGIA, 2001.

BARRETTO FILHO, Henyo Trindade. Tapebas, tapebanos e pernas-de-pau de Caucaia, Ceará: da etnogênese como processo social e luta simbólica. Brasília, DF: Universidade de Brasília, 1994. (Série Antropologia, n. 165).

BITTAR, Marisa. Geopolítica e separatismo na elevação de Campo Grande a capital. Campo Grande: Ed. UFMS, 1999.

BRASIL. Constituição (1988). Constituição da República Federativa do Brasil. Brasília, DF: Senado, 1988.

BRASIL. Censo demográfico 2000/2010. Rio de Janeiro: Instituto Brasileiro de Geografia e Estatística, 2010.

CABRAL, Paulo Eduardo. Educação escolar indígena em Mato Grosso do Sul: algumas reflexões. Campo Grande: SED/MS, 2002.

CARDOSO DE OLIVEIRA, Roberto. Do índio ao bugre: o processo de assimilação dos Terena. 2. ed. Rio de Janeiro: Francisco Alves, 1976.

CARVALHO, Maria Rosário Gonçalves de. A identidade dos povos indígenas no Nordeste. Anuário Antropológico, Rio de Janeiro/Fortaleza, v. 4, p. 169-188, 1984.

CHAMORRO, Graciela; COMBÈS, Isabelle (Org.). Povos indígenas em Mato Grosso do Sul: história, cultura e transformações sociais. Dourados, MS: Ed. UFGD, 2015.

FARIA, Ivani Ferreira de. Território e territorialidades indígenas do Alto Rio Negro. Manaus: Edua, 2003. 
FENTRESS, James; WICKHAM, Chris. Memória social: novas perspectivas sobre o passado. Lisboa: Teorema, 1992.

GRÜNEWALD, Rodrigo de Azeredo. "Regime de Índio" e faccionalismo: os Atikum da Serra do Umã. 238 f. Dissertação (Mestrado em Antropologia Social) - Universidade Federal do Rio de Janeiro, Rio de Janeiro, 1993.

GRÜNEWALD, Rodrigo de Azeredo. Etnogênese e 'regime de índio' na Serra do Umã. In: OLIVEIRA, João Pacheco de (Org.). A viagem da volta: etnicidade, política e reelaboração cultural no Nordeste indígena. 2. ed. Rio de Janeiro: Contracapa/Laced, 2004. p. 139-174.

HAESBAERT, Rogério. Dos múltiplos territórios à multiterritorialidade. 2004. Disponível em: <http://www.ufrgs.br/petgea/Artigo/rh.pdf>. Acesso em: 22 ago. 2019.

HAESBAERT, Rodrigo. Viver no limite: território e multi/transterritorialidade em tempos de in-segurança e contenção. Rio de Janeiro: Bertrand Brasil, 2014.

HALL, Stuart. Da diáspora: identidades e mediações culturais. Belo Horizonte: Ed. UFMG, 2008.

JOSÉ DA SILVA, Giovani. Da terra seca à condição de índios “terra seca": os Atikum em Mato Grosso do Sul. 58 f. Monografia (Especialização em Antropologia) - Universidade Federal de Mato Grosso, Cuiabá, 2000.

JOSÉ DA SILVA, Giovani. "Terra seca” à vista: os Atikum em Mato Grosso do Sul. In: SALOMON, Marlon; SILVA, Joana Fernandes; ROCHA, Leandro Mendes (Org.). Processos de territorialização: entre a história e a antropologia. Goiânia: Ed. UCG, 2005. p. 55-80.

JOSÉ DA SILVA, Giovani. Ressurgidos, emergentes, resistentes: reflexões sobre as presenças indígenas Atikum, Kamba e Kinikinau em Mato Grosso do Sul. In: SEMANA DE HISTÓRIA DA UFMS, 5., 2007, Três Lagoas. Anais ... Campo Grande: Universidade Federal de Mato Grosso do Sul, 2007.

JOSÉ DA SILVA, Giovani. A presença Camba-Chiquitano na fronteira Brasil-Bolívia (19381987): identidades, migrações e práticas culturais. 292 f. Tese (Doutorado em História) Universidade Federal de Goiás, Goiânia, 2009.JOSÉ DA SILVA, Giovani. Identidades cambiantes: os Kamba na fronteira Brasil-Bolívia. Goiânia: Ed. UFG, 2012.

JOSÉ DA SILVA, Giovani. A Reserva Indígena Kadiwéu (1899-1984): memória, identidade e história. Dourados, MS: Ed. UFGD, 2014. 
JOSÉ DA SILVA, Giovani. “Todo se cambia, incluso el paisaje”: memórias indígenas e migração Camba-Chiquitano. História em Reflexão: Revista Eletrônica de História, Dourados, v. 9, n. 17, p. 1-21, 2015.

JOSÉ DA SILVA, Giovani. Atikum: os índios negros de Mato Grosso do Sul. Curitiba: CRV, 2019.

JOSÉ DA SILVA, Giovani; BOLZAN, Aila Villela; SOUZA, Rosaldo de Albuquerque (Org.). Kinikinau: arte, história, memória \& resistência. Curitiba: CRV, 2017.

JOSÉ DA SILVA, Giovani; SOUZA, José Luiz de. O despertar da fênix: a educação escolar como espaço de afirmação da identidade étnica Kinikinau em Mato Grosso do Sul. Sociedade e Cultura, Goiânia, v. 6, n. 2, p. 149-156, 2003.

JOSÉ DA SILVA, Giovani; SOUZA, José Luiz de. História, etnicidade e cultura em fronteiras: os Kinikinau em Mato Grosso do Sul. In: ROCHA, Leandro Mendes; BAINES, Stephen Grant (Org.). Fronteiras e espaços interculturais: transnacionalidade, etnicidade e identidade em regiões de fronteira. Goiânia: Ed. UCG, 2008. p. 21-36.

LE GOFF, J. História e memória. 2. ed. Campinas, SP: Unicamp, 1992.

LITTLE, Paul. Territórios sociais e povos tradicionais no Brasil: por uma antropologia da territorialidade. Brasília, DF: Universidade de Brasília, 2002. (Série Antropologia, n. 322).

MANCUSO, Maria Inês Rauter. Memória: representação, identidade e felicidade. Cultura Vozes, Petrópolis, v. 94, n. 4, p. 66-87, 2000.

MANGOLIM, Olívio. Povos indígenas em Mato Grosso do Sul: viveremos por mais 500 anos. Campo Grande: Cimi/MS, 1993.

NORA, Pierre. Entre memória e história: a problemática dos lugares. Projeto História, São Paulo, n. 10, p. 7-28, 1993.

OLIVEIRA, João Pacheco de. Redimensionando a questão indígena no Brasil: uma etnografia das terras indígenas. In: OLIVEIRA, João Pacheco de (Org.). Indigenismo e territorialização: poderes, rotinas e saberes coloniais no Brasil contemporâneo. Rio de Janeiro: Contracapa, 1998. p. 15-42.

OLIVEIRA, João Pacheco de. Uma etnologia dos “índios misturados"? Situação colonial, territorialização e fluxos culturais. In: OLIVEIRA, João Pacheco de (Org.). A viagem da volta: etnicidade, política e reelaboração cultural no Nordeste indígena. 2. ed. Rio de Janeiro: Contracapa/Laced, 2004. p. 13-42. 
OLIVEIRA, Jorge Eremites de. A história indígena em Mato Grosso do Sul, Brasil: dilemas e perspectivas. Territórios e Fronteiras, Cuiabá, v. 2, n. 2, p. 115-124, 2001.

OLIVEIRA, Jorge Eremites de. A História dos povos indígenas no Brasil e a história indígena em Mato Grosso do Sul. In: REGO, André de Almeida; APOLINÁRIO, Juciene Ricarte (Org.). Novas histórias dos povos indígenas no Brasil: territorialidades da escrita interdisciplinar indígena e não indígena. Salvador: Saga, 2018. p. 13-38.

PENTEADO, Yara Maria Brum A condição urbana: estudo de dois casos de inserção do índio na vida citadina. 118 f. Dissertação (Mestrado em Antropologia) - Universidade de Brasília, Brasília, 1980.

POLLACK, Michael. Memória, esquecimento, silêncio. Estudos Históricos, Rio de Janeiro, v. 2, n. 3, p. 3-15, 1989.

POLLACK, Michael. Memória e identidade social. Estudos Históricos, Rio de Janeiro, v. 5, n. 10, p. 200-215, 1992.

RAFFESTIN, Claude. Por uma geografia do poder. São Paulo: Ática, 1993.

RIBEIRO, Darci. Os índios e a civilização: a integração das populações indígenas no Brasil moderno. Rio de Janeiro: Civilização Brasileira, 1970.

SANSON, Cesar. Mato Grosso do Sul: onde um boi vale mais que uma criança indígena. 2014. Disponível em: <http://www.ihu.unisinos.br/noticias/535838-mato-grosso-do-sulonde-um-boi-vale-mais-que-uma-crianca-indigena>. Acesso em: 30 abr. 2019.

SANTOS, Lucicleide Gomes dos. Cerâmica Kinikinau: a arte de um povo tido como extinto. 124 f. Dissertação (Mestrado em História) - Universidade Federal da Grande Dourados, Dourados, 2011.

SCHADEN, Egon. Leituras de etnologia brasileira. São Paulo: Ed. Nacional, 1976.

SEEGER, Anthony; CASTRO, Eduardo B. Viveiros de. Terras e territórios indígenas no Brasil. Encontros com a Civilização Brasileira, Rio de Janeiro, v. 12, p. 101-109, 1979.

SILVA, Georgia da. "Chama os Atikum que eles desatam já": práticas terapêuticas, sabedores e poder. 115 f. Dissertação (Mestrado em Antropologia) - Universidade Federal de Pernambuco, Recife, 2007.

SILVA, Ruth Henrique da. Brasileiros, bolivianos ou indígenas? Construções identitárias dos Camba no Brasil, 207 f. Tese (Doutorado em Antropologia) - Universidade Federal Fluminense, Niterói, 2009. 
TOURINHO NETO, Fernando da Costa. Os direitos originários dos índios sobre as terras que ocupam e suas consequências jurídicas. In: SANTILLI, Juliana (Coord.). Os direitos indígenas e a constituição. Porto Alegre: NDI/Sérgio Antonio Fabris, 1993. p. 9-43.

ULIAN, Gabriel. “Eu ando em terra alheia, procurando a minha aldeia": territorialização dos Atikum em Mato Grosso do Sul. 128 f. Dissertação (Mestrado em Antropologia) Universidade Federal da Grande Dourados, Dourados, 2013.

WALSH, Catherine. Interculturalidade, crítica e pedagogia decolonial: in-surgir, re-existir e re-viver. In: CANDAU, Vera Maria (Org.). Educação intercultural na América Latina: entre concepções, tensões e propostas. Rio de Janeiro: 7 Letras, 2009. p. 12-42y. 